\title{
Long-term exposure to trihalomethanes in drinking water and breast cancer in the Spanish multicase-control study on cancer (MCC-SPAIN) ${ }^{\text {is }}$
}

\author{
Laia Font-Riberaa,b,c,d ${ }^{\mathrm{a}}$ Esther Gràcia-Lavedan ${ }^{\mathrm{a}, \mathrm{c}, \mathrm{d}}$, Nuria Aragonés ${ }^{\mathrm{d}, \mathrm{e}}$, Beatriz Pérez-Gómez ${ }^{\mathrm{d}, \mathrm{e}}$, \\ Marina Pollán ${ }^{\mathrm{d}, \mathrm{e}, \mathrm{f}}$, Pilar Amiano ${ }^{\mathrm{d}, \mathrm{g}}$, Ana Jiménez-Zabala ${ }^{\mathrm{g}}$, Gemma Castaño-Vinyals ${ }^{\mathrm{a}, \mathrm{b}, \mathrm{c}, \mathrm{d}}$, \\ Aina Roca-Barceló $^{\mathrm{h}}$, Eva Ardanaz ${ }^{\mathrm{d}, \mathrm{i}}$, Rosana Burgui ${ }^{\mathrm{d}, \mathrm{i}}$, Antonio José Molina ${ }^{\mathrm{j}}$, \\ Tania Fernández-Villa ${ }^{\mathrm{j}}$, Inés Gómez-Acebo ${ }^{\mathrm{k}}$, Trinidad Dierssen-Sotos ${ }^{\mathrm{k}}$, Victor Moreno ${ }^{1, \mathrm{~m}, \mathrm{~d}, \mathrm{n}}$, \\ Guillermo Fernandez-Tardon $^{\mathrm{d}, \mathrm{o}}$, Rosana Peiró ${ }^{\mathrm{d}, \mathrm{p}}$, Manolis Kogevinas ${ }^{\mathrm{a}, \mathrm{b}, \mathrm{c}, \mathrm{d}}$, \\ Cristina M. Villanueva ${ }^{\mathrm{a}, \mathrm{b}, \mathrm{c}, \mathrm{d}, *}$ \\ a ISGlobal, Barcelona, Spain \\ ' IMIM (Hospital del Mar Medical Research Institute), Barcelona, Spain \\ ${ }^{\mathrm{c}}$ Department of Experimental and Health Sciences, Universitat Pompeu Fabra (UPF), Barcelona, Spain \\ ${ }^{\mathrm{d}}$ CIBER Epidemiología y Salud Pública (CIBERESP), Madrid, Spain \\ e Cancer and Environmental Epidemiology Unit, National Centre for Epidemiology, Carlos III Institute of Health, Madrid, Spain \\ ${ }^{\mathrm{f}}$ Cancer Epidemiology Research Group, Oncology and Hematology Area, IIS Puerta De Hierro, Madrid, Spain \\ ${ }^{g}$ Public Health Division of Gipuzkoa, Biodonostia Research Institute, San Sebastian, Spain \\ h Epidemiology Unit and Girona Cancer Registry, Oncology Coordination Plan, Department of Health, Autonomous Government of Catalonia, Catalan Institute of \\ Oncology, Girona, Spain \\ i Instituto de Salud Pública y Laboral de Navarra, Pamplona, Spain \\ ${ }^{\mathbf{j}}$ Grupo de Investigación en Interacciones Gen-Ambiente y Salud, Universidad de León, Spain \\ ${ }^{\mathrm{k}}$ Department of Preventive Medicine and Public Health, University of Cantabria, Santander, Spain \\ ${ }^{1}$ Unit of Biomarkers and Susceptibility, Cancer Prevention and Control Program, Catalan Institute of Oncology (ICO), Hospitalet de Llobregat, Spain \\ ${ }^{\mathrm{m}}$ Colorectal Cancer Group, Bellvitge Biomedical Research Institute (IDIBELL), Hospitalet de Llobregat, Spain \\ ${ }^{\mathbf{n}}$ Department of Clinical Sciences, Faculty of Medicine, University of Barcelona, Barcelona, Spain \\ ${ }^{\circ}$ University of Oviedo, Asturias, Spain \\ Pentre for Research in Public Health, Valencia, Spain
}

\section{A R T I C L E I N F O}

\section{Keywords:}

Trihalomethanes

Drinking water

Long-term exposure

Exposure routes

Case-control study

\begin{abstract}
A B S T R A C T
Background: Exposure to trihalomethanes (THMs) in drinking water has consistently been associated with an increased risk of bladder cancer, but evidence on other cancers including the breast is very limited.

Objectives: We assessed long-term exposure to THMs to evaluate the association with female breast cancer (BC) risk.

Methods: A multi case-control study was conducted in Spain from 2008 to 2013. We included 1003 incident BC cases (women 20-85 years old) recruited from 14 hospitals and 1458 population controls. Subjects were interviewed to ascertain residential histories and major recognized risk factors for BC. Mean residential levels of chloroform, brominated THMs (Br-THMs) and the sum of both as total THM (TTHMs) during the adult-lifetime were calculated.

Results: Mean adult-lifetime residential levels ranged from 0.8 to $145.7 \mu \mathrm{g} / \mathrm{L}$ for TTHM (median $=30.8$ ), from 0.2 to $62.4 \mu \mathrm{g} / \mathrm{L}$ for chloroform (median $=19.7$ ) and from 0.3 to $126.0 \mu \mathrm{g} / \mathrm{L}$ for Br-THMs (median = 9.7). Adult-lifetime residential chloroform was associated with BC (adjusted OR $=1.47$; 95\%CI $=1.05,2.06$ for the highest $(>24 \mu \mathrm{g} / \mathrm{L})$ vs. lowest $(<8 \mu \mathrm{g} / \mathrm{L})$ quartile; p-trend $=0.024)$. No association was detected for residential $\mathrm{Br}$-THMs $(\mathrm{OR}=0.91 ; 95 \% \mathrm{CI}=0.68,1.23$ for $>31 \mu \mathrm{g} / \mathrm{L}$ vs. $<6 \mu \mathrm{g} / \mathrm{L})$ or TTHMs $(\mathrm{OR}=1.14$; $95 \% \mathrm{CI}=0.83,1.57$ for $>48 \mu \mathrm{g} / \mathrm{L}$ vs. $<22 \mu \mathrm{g} / \mathrm{L})$.

Conclusions: At common levels in Europe, long-term residential total THMs were not related to female breast cancer. A moderate association with chloroform was suggested at the highest exposure category. This large
\end{abstract}

\footnotetext{
Conflicts of interest: none.

* Corresponding author at: Barcelona Institute for Global Health (ISGlobal), Doctor Aiguader, 88, 08003 Barcelona, Spain.

E-mail address: cristina.villanueva@isglobal.org (C.M. Villanueva).
} 
epidemiological study with extensive exposure assessment overcomes several limitations of previous studies but further studies are needed to confirm these results.

\section{Introduction}

Breast cancer (BC) is the first cancer in incidence and mortality among women world-wide (GLOBOCAN, 2012), with an increasing incidence during the last decades, also in Spain (Pollán et al., 2009). BC is more common in western countries and among favoured socioeconomic status (Brody and Rudel, 2003). Main recognized risk factors affect endogenous estrogenic levels (Hankinson et al., 2004) and include sex, age, body mass index, early age at menarche, advanced age at first delivery and at menopause, life-style factors such as alcohol consumption and low physical activity, and drugs with estrogenic action before or after menopause (Hankinson et al., 2004). Established risk factors explain approximately $50 \%$ of the variability in BC incidence, and other environmental factors may partly explain the remaining variation (Brody et al., 2007). Toxicological studies, and to a lesser extend epidemiological studies, have related some environmental exposures to BC (Macon and Fenton, 2013), mainly through endocrine disruption (Brody and Rudel, 2003). Drinking water disinfection byproducts (DBP) are among the chemicals suggested by toxicologic research as potentially related to $\mathrm{BC}$ that have not been investigated enough in epidemiologic studies (Brody et al., 2007).

DBPs are a mixture of hundreds of chemicals formed in water during the disinfection process. This is a ubiquitous exposure through ingestion of tap water, inhalation and dermal exposure during showering, bathing or washing dishes (Villanueva et al., 2015). The most prevalent DBP in drinking water are trihalomethanes (THM), which are the only DBP group regulated in the EU with a maximum contaminant level of $100 \mu \mathrm{g} / \mathrm{L}$. Several DBPs have been shown to be genotoxic in in vitro assays and carcinogenic in animal experiments (Richardson et al., 2007) and the WHO International Agency for Research on Cancer (IARC) classifies chloroform and other widespread DBP as possible humans carcinogens (Villanueva et al., 2015). Several epidemiological studies have related exposure to DBPs and cancer risk, being the most consistent evidence for bladder cancer and in a lower extent for colon and rectal cancer (Villanueva et al., 2015). Only sporadic epidemiological studies have assessed the impact of DBPs on other cancer sites including the breast (Villanueva et al., 2015).

Among the few epidemiological studies on DBP exposure and BC, some detected a positive association (Doyle et al., 1997; Gottlieb et al., 1982; Koivusalo et al., 1997; Wilkins and Comstock, 1981), while others did not (Kanarek and Young, 1982; Marcus et al., 1998; Vinceti et al., 2004; Young et al., 1981; Zierler et al., 1986). These are studies conducted 20 years ago (Doyle et al., 1997; Koivusalo et al., 1997; Marcus et al., 1998) or 30 (Gottlieb et al., 1982; Kanarek and Young, 1982; Wilkins and Comstock, 1981; Young et al., 1981; Zierler et al., 1986) with only one exception (Vinceti et al., 2004) and had important methodological limitations, including an ecological design (Marcus et al., 1998; Vinceti et al., 2004; Wilkins and Comstock, 1981), a poor control for confounding and a very limited exposure assessment based on surrogates of DBP exposure (Doyle et al., 1997; Gottlieb et al., 1982; Kanarek and Young, 1982; Koivusalo et al., 1997; Young et al., 1981). Furthermore, evidence that 3-Chloro-4-(dichloromethyl)-5-hydroxy$2(5 \mathrm{H})$-furanone (MX), a major mutagenic constituent of DBP, causes mammary tumours in rats (Komulainen et al., 1997) also suggests that the association between DBP exposure and BC should be further investigated in epidemiological studies overcoming the limitations of previous studies (Brody et al., 2007).

We aim to provide new epidemiological evidence on the association between lifetime exposure to DBPs and female BC risk in a large casecontrol study, including areas with contrasting THM concentrations in Spain and evaluating different routes of exposure and THM species.

\section{Methods}

\subsection{Study design and population}

A multi case-control study was conducted from 2008 to 2013 in twelve provinces of Spain (MCC-Spain project) (Castaño-Vinyals et al., 2015). Women $20-85$ years old with histologically confirmed incident BC (International Classification of Diseases 10th Revision [ICD-10]: C50, D05.1, D05.7) without personal cancer history were recruited from oncologic and surgical services in fourteen hospitals from eight provinces. Controls were selected randomly from the rosters of General Practitioners at the Primary Health Centers participating in the study covering nearly all the population living in the corresponding area, allowing to identify population-based controls from the same study base as cases. Controls were frequency matched to cases by age in 5year age groups and study area. They were contacted on behalf of their General Practitioner and invited to participate in the study. Subjects with serious barriers to communication were excluded. Average response rate was $71 \%$ for cases and $53 \%$ for controls. The study protocol was approved by the ethical review board from participating centers and all participants signed an informed consent before recruitment.

\subsection{Individual information}

A structured computerized questionnaire was administered by trained personnel in face-to-face interviews to collect data on residential history, water source in each residence (bottled, tap, other) and frequency and duration of bathing, showering and hand dishwashing. Several potential risk factors were also collected including age (continuous), educational level (less than primary school, primary school, secondary school, university), occupational status (working, not working, housewife, retired), race (white, others), weight and height to compute body mass index (BMI; $<25,25-29.9$, $\geq 30$ ), family history of BC (yes, no), menopausal status (pre, post), menopause treatment (ever, never), oral contraceptive use (never, ever), nulliparity (yes, no), age at menarche (continuous, and categorized to: $\leq 12$, $13-14,>14$ years), age at first birth (continuous, further categorized to: $<25,25-28,>28$ years), breastfeeding (continuous, further categorized to: $0,>0-6,>6-12,>12$ months), smoking (never, former, current), average leisure physical activity in the last 10 years (continuous frequency and duration converted to metabolic equivalents of task (METS)/hour/week). Diet habits and alcohol consumption was reported through a self-administered semi-quantitative food-frequency questionnaire and current energy intake $(<1500$, $1500-2000,>2000 \mathrm{kcal} /$ day) and alcohol intake in the past $(0$, $0-5.5$, > $5.5 \mathrm{~g} /$ day) were calculated. Long-term waterborne ingested nitrate was also estimated (Espejo-Herrera et al., 2016) and levels were categorized in quartiles. Missing data in categorical variables were classified as a separate category.

\subsection{Historical trihalomethane levels in the study area}

We used trihalomethanes as a surrogate of DBPs. We collected historical information on water source, treatment and routine THM measurements in the study areas through water utilities, local authorities and health authorities. Historical THM levels back to 1940 were modeled at water zone level, the minimum geographic unit with homogeneous water source, treatment and THM levels (corresponding to municipality in most cases). Annual average THM levels were calculated using available measurements. For years when THM measurements were absent, available THM levels were averaged and imputed if 
water source and treatment were unchanged. Proportion of surface water and type of treatment were used as a weight to this average in the event of changes in water source and treatment. Before chlorination started, THM levels were assumed to be zero. Total THMs (TTHMs) was calculated summing up the concentrations of the four THMs (chloroform, bromodichloromethane, dibromochloromethane, and bromoform). Brominated THMs (Br-THMs) were calculated as the TTHMs excluding chloroform. Correlation between residential levels of chloroform, Br-THMs and TTHMs was explored with Spearman correlation.

\subsection{Individual exposure in the study population}

THM levels and subjects' personal data were linked by year and water zone of residence to obtain an annual average THM level in the residences where subjects lived from age 18 to 2 years before the interview. Average levels in all residences with THM estimates was then calculated and referred as adult-lifetime residential levels. Average residential THM levels in the last 10 years were also calculated as an alternative exposure window with more accurate exposure estimates. The type of water consumed in the residence and liters/day ingested were used to calculate ingested THM levels, by multiplying residential levels if tap water was consumed, and a zero THM level if water ingested was bottled (Font-Ribera et al., 2010). When water consumed was from private wells, levels assigned were $0.3,0.3,0.8$, and $1.8 \mu \mathrm{g} / \mathrm{L}$ respectively for chloroform, bromodichloromethane, dibromochloromethane and bromoform, according to unpublished records from wells in the study areas. Average ingested TTHMs and Br-THMs level in the residences was calculated for the years with available data and expressed as $\mu \mathrm{g} /$ day. Exposure through showering, bathing and hand dish-washing was estimated by multiplying minutes/week of each activity by the residential TTHMs or Br-THMs level and expressed as $\mu \mathrm{g} /$ $\mathrm{L} \times$ min/week. When gloves were used "most of the time" for hand dish-washing (16.9\% of subjects), half of the THM exposure was assigned.

\subsection{Statistical analysis}

The initial sample of BC cases and controls in the study areas with modeled THM was 3322 (1582 cases and 1740 controls). Only subjects with known THM concentrations in the residential tap water for at least $70 \%$ of the years between age 18 to 2 years before the interview $(87 \%$ of interviewed subjects) were included. In order to have a similar geographical distribution of cases and controls, only municipalities with at least one case and one control were included and 9 controls and 278 cases living in 117 small municipalities not accomplishing these criteria were excluded. One subject with unreliable interview was further excluded, as well as fourteen controls that had missing data in physical activity, a variable included in all final models. Analyzed sample included 2461 subjects, 1003 cases and 1458 controls.

The main models estimated the association between $\mathrm{BC}$ and average adult-lifetime residential TTHMs, chloroform and Br-THMs levels. Generalized additive models (GAM) were used to evaluate the exposure-response relationships on continuous variables. Exposure variables were categorized into quartiles defined according to the exposure distribution among controls. We estimated odds ratios (OR) and 95\% confidence intervals (CI) of BC using mixed models with recruitment area as random effect. Additional models explored the association with residential THM levels in the last 10 years, mutual adjustment between residential chloroform and residential $\mathrm{Br}$-THMs as well as interaction by menopausal status. We estimated OR of BC for specific exposure routes: drinking water source in the longest residence, time showering, time washing dishes by hand, THM exposure through ingestion, through showering and through hand dish-washing.

All models were adjusted for age, area and education. Further adjustment included known risk factors for BC that were significant in the
Table 1

Description of the study population. $\mathrm{N}=2461$.

\begin{tabular}{|c|c|c|c|c|c|}
\hline & \multicolumn{2}{|c|}{ Controls } & \multicolumn{2}{|c|}{ Cases } & \multirow[t]{2}{*}{ p-Value } \\
\hline & $\mathrm{N}$ & $\%$ & $\mathrm{~N}$ & $\%$ & \\
\hline Total & 1458 & & 1003 & & \\
\hline \multicolumn{6}{|l|}{ Area } \\
\hline Asturias & 90 & 6.2 & 62 & 6.2 & \\
\hline Barcelona A & 140 & 9.6 & 114 & 11.4 & \\
\hline Barcelona B & 89 & 6.1 & 45 & 4.5 & \\
\hline Barcelona C & 93 & 6.4 & 47 & 4.7 & \\
\hline Cantabria & 149 & 10.2 & 86 & 8.6 & \\
\hline Guipuzcoa & 239 & 16.4 & 119 & 11.9 & \\
\hline León & 151 & 10.4 & 128 & 12.8 & \\
\hline Madrid & 305 & 20.9 & 236 & 23.5 & \\
\hline Navarra & 150 & 10.3 & 115 & 11.5 & \\
\hline Valencia & 52 & 3.6 & 51 & 5.1 & \\
\hline \multicolumn{6}{|l|}{ Age, years } \\
\hline Mean (SD) & 59.4 & $(12.8)$ & 57.1 & $(12.0)$ & \\
\hline$\leq 50$ & 412 & 28.3 & 334 & 33.3 & \\
\hline $51-60$ & 346 & 23.7 & 278 & 27.7 & \\
\hline $61-70$ & 366 & 25.1 & 246 & 24.5 & \\
\hline$>70$ & 334 & 22.9 & 145 & 14.5 & \\
\hline \multicolumn{6}{|l|}{ Education } \\
\hline$<$ Primary school & 243 & 16.7 & 144 & 14.4 & 0.417 \\
\hline Primary school & 465 & 31.9 & 331 & 33.0 & \\
\hline Secondary school & 448 & 30.7 & 325 & 32.4 & \\
\hline University & 302 & 20.7 & 203 & 20.2 & \\
\hline \multicolumn{6}{|l|}{ Menopausal status } \\
\hline Post & 1063 & 72.9 & 671 & 66.9 & 0.005 \\
\hline Pre & 393 & 27.0 & 331 & 33.0 & \\
\hline $\mathrm{DK} / \mathrm{M}$ & 2 & 0.1 & 1 & 0.1 & \\
\hline \multicolumn{6}{|c|}{ Family history of breast cancer } \\
\hline No & 1149 & 78.8 & 651 & 64.9 & $<0.001$ \\
\hline Yes & 252 & 17.3 & 321 & 32.0 & \\
\hline $\mathrm{DK} / \mathrm{M}$ & 57 & 3.9 & 31 & 3.1 & \\
\hline \multicolumn{6}{|l|}{ Body mass index, $\mathrm{kg} / \mathrm{m}^{2}$} \\
\hline$<25$ & 745 & 51.1 & 477 & 47.6 & 0.189 \\
\hline $25-29.9$ & 452 & 31.0 & 342 & 34.1 & \\
\hline 30 or more & 261 & 17.9 & 184 & 18.3 & \\
\hline \multicolumn{6}{|l|}{ Occupational status } \\
\hline Working & 556 & 38.1 & 483 & 48.2 & $<0.001$ \\
\hline Not working & 87 & 6.0 & 71 & 7.1 & \\
\hline Housewife & 480 & 32.9 & 247 & 24.6 & \\
\hline Retired & 335 & 23.0 & 202 & 20.1 & \\
\hline \multicolumn{6}{|l|}{ Oral contraceptive use } \\
\hline Never & 805 & 55.2 & 560 & 55.8 & 0.353 \\
\hline Ever & 652 & 44.7 & 440 & 43.9 & \\
\hline $\mathrm{DK} / \mathrm{M}$ & 1 & 0.1 & 3 & 0.3 & \\
\hline \multicolumn{6}{|l|}{ Menopause treatment } \\
\hline Ever & 294 & 20.2 & 150 & 15.0 & $<0.001$ \\
\hline Never & 765 & 52.5 & 515 & 51.4 & \\
\hline Missing/Pre-menopause & 399 & 27.4 & 338 & 33.7 & \\
\hline \multicolumn{6}{|l|}{ Physical activity ${ }^{\mathrm{a}}$, METs } \\
\hline 0 & 891 & 61.1 & 676 & 67.4 & 0.002 \\
\hline$>0$ to 8 & 272 & 18.7 & 162 & 16.2 & \\
\hline$>10$ to 16 & 121 & 8.3 & 84 & 8.4 & \\
\hline$>16$ & 174 & 11.9 & 81 & 8.1 & \\
\hline \multicolumn{6}{|l|}{ Energy intake, kcal/day } \\
\hline$<1500$ & 452 & 31.0 & 251 & 25.0 & 0.007 \\
\hline $1500-2000$ & 485 & 33.3 & 352 & 35.1 & \\
\hline$>2000$ & 351 & 24.1 & 284 & 28.3 & \\
\hline $\mathrm{DK} / \mathrm{M}$ & 170 & 11.7 & 116 & 11.6 & \\
\hline
\end{tabular}

DK/M: Don't know or missing.

${ }^{\text {a }}$ Physical activity: metabolic equivalents (MET) total h/week; annual median in the last 10 years.

models (p-value $<0.05$ ) and those that changed the risk estimates (beta) $>10 \%$. Main models were adjusted for area, age, educational level, occupational status, family history of BC, BMI, energy intake, physical activity, oral contraceptive use and menopause treatment use. Multicollineality was explored using the variance inflation factor (VIF), having all variable categories a VIF $<4$ (except the highest quartile of TTHM and three study areas) with a mean of 2.66 in the model for lifetime average residential TTHM. Statistical analyses were performed 
using STATA version 12.0 (Stata Corp, College Station, TX).

\section{Results}

1003 cases and 1458 controls were included from ten study areas in Spain (Table 1). After adjusting by area, age and educational level, cases showed higher frequencies of family history of BC, overweight and obesity, occupational status, never use of menopause treatment, never use of oral contraceptives, being physically inactive and high energy intake. The OR of BC for these and other classical BC risk factors can be found in Table S1. Compared to women excluded for the final analysis, the included population had a higher proportion of controls, postmenopausal women, and a lower proportion of women of young age, working status and highest energy intake (Table S1). The geographical distribution of the residencies of cases and controls is shown in Fig. S1.

Average adult-lifetime residential levels of TTHMs ranged from 0.8 to $145.7 \mu \mathrm{g} / \mathrm{L}$ among study participants (Fig. 1), with a median level of $30.8 \mu \mathrm{g} / \mathrm{L}$ (interquartile range (IQR) $=22.3,51.6$ ) for TTHMs, $19.7 \mu \mathrm{g} /$ $\mathrm{L}(\mathrm{IQR}=7.8,24.5)$ for chloroform and $9.7 \mu \mathrm{g} / \mathrm{L}(\mathrm{IQR}=5.3,28.5)$ for Br-THMs. Exposure to residential chloroform ranged between 0.8 and $62.4 \mu \mathrm{g} / \mathrm{L}$, while exposure to Br-THMs ranged from 1.9 to $126.0 \mu \mathrm{g} / \mathrm{L}$. The variability of residential THMs within area was small for several

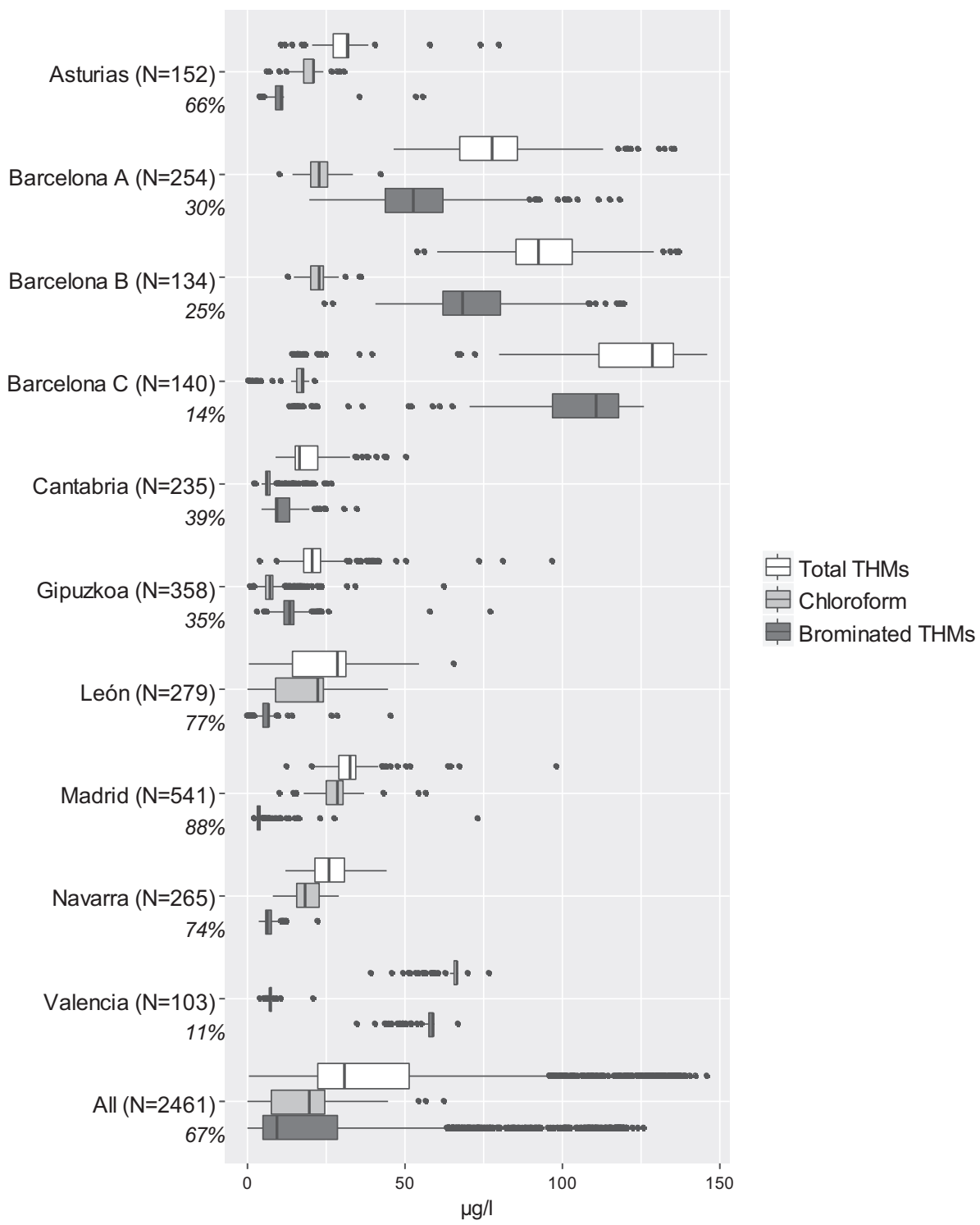

areas, what precluded the estimation of overall effects through metaanalysis. The proportion of chloroform from TTHMs differed among areas, from $11 \%$ in Valencia to $88 \%$ in Madrid, and the Spearman correlation between chloroform and Br-THMs also differed between areas, being -0.26 overall (Fig. S2).

Generalized additive models showed a positive linear relationship between BC and average adult-lifetime residential levels of TTHMs, chloroform and Br-THM (Fig. 2). When exposure was categorized into quartiles, no significant association was seen between BC and TTHMs or Br-THMs (Table 2). The OR for the highest vs. lowest quartile of TTHM $(>48.3 \mu \mathrm{g} / \mathrm{L}$ vs. $\leq 21.7 \mu \mathrm{g} / \mathrm{L})$ was $1.14(95 \% \mathrm{CI}=0.83,1.57)$. Residential levels of chloroform were related to $\mathrm{BC} \quad(\mathrm{OR}=1.47$ $(95 \% \mathrm{CI}=1.05,2.06)$ for the highest vs. lowest quartile $(>24.3 \mu \mathrm{g} / \mathrm{L}$ vs. $\leq 7.6 \mu \mathrm{g} / \mathrm{L}$ )) and a p-trend value of 0.028 . A positive association was also observed with residential chloroform as a continuous variable with an OR of $1.12(0.98,1.27)$ for a $10 \mu \mathrm{g} / \mathrm{L}$ increase. After further adjustment for residential levels of Br-THMs, the association between $\mathrm{BC}$ and residential chloroform remained very similar and there was no collinearity in the model (mean VIF for the two variables $=1.89$ ). No significant interaction was observed between residential THM levels and menopausal status on BC risk, although slightly higher associations among pre-menopausal women were found at the highest exposure category (Table S3). Likewise, no interaction was observed between

Fig. 1. Average adult-lifetime residential levels of total trihalomethanes (TTHMs), chloroform and brominated trihalometanes (Br-THMs) among the study participants in the 10 study areas. $\mathrm{N}=2461$.

The percentage in italics indicates de proportion of TTHMs that is chloroform. The vertical line inside each box in dicates the median value. The lower and upper hinges of the boxes indicate the 25th and 75th percentile. 

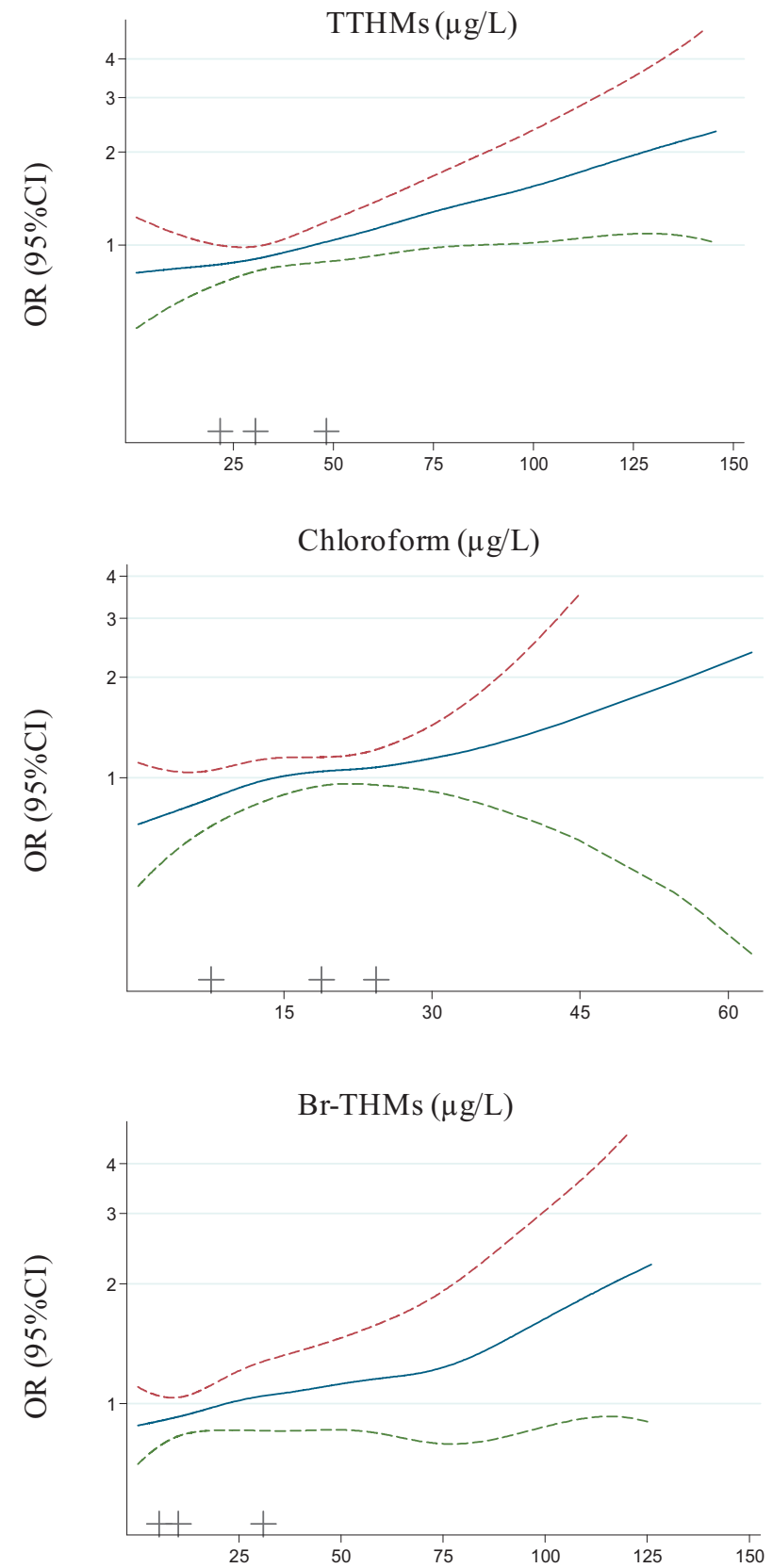

Fig. 2. Exposure-response curves between adult-lifetime residential THMs $(\mu \mathrm{g} / \mathrm{L})$ and breast cancer from generalized additive models. $\mathrm{N}=2461$ (1003 cases and 1458 controls).

Tick marks above the x-axes represent quartiles of exposure. Models adjusted by area, age, educational level, occupational status, family history of BC, BMI, energy intake, physical activity, oral contraceptive use and menopause treatment use. P-values for nonlinearity: 0.616 for TTHMs, 0.473 for chloroform, 0.300 for Br-THMs.

residential TTHMs and chloroform levels and educational level on BC risk, while a significant interaction was detected for Br-THMs level. The OR for BC among those in the highest vs. lowest quartile of residential $\mathrm{Br}$-THMs level was lower among those with primary or less education $(\mathrm{OR}=0.69 ; 95 \% \mathrm{CI}=0.48,1.01)$ than among those with secondary or more education $(\mathrm{OR}=1.36 ; 95 \% \mathrm{CI}=0.83,2.24)$ (Table S4). Further adjustment of the residential THM models by other socioeconomic status variables (partner educational level, social class by the largest occupation and parental socioeconomic status) gave similar results (Table S5).

In the Barcelona metropolitan area, with the highest levels of $\mathrm{Br}$ THMs and TTHMs, exposure to residential Br-THMs and TTHMs were
Table 2

Odds ratio (OR) and 95\% confidence interval (CI) of breast cancer associated with adultlifetime residential levels of total trihalomethanes (TTHMs), chloroform and brominated trihalometanes (Br-THMs). $\mathrm{N}=2461$.

\begin{tabular}{|c|c|c|c|c|c|c|}
\hline & Controls & Cases & $\mathrm{OR}^{\mathrm{a}}$ & (95\%CI) & $\mathrm{OR}^{\mathrm{b}}$ & $95 \% \mathrm{CI}$ \\
\hline \multicolumn{7}{|l|}{ TTHMs $(\mu \mathrm{g} / \mathrm{L})$} \\
\hline$\leq 21.7$ & 365 & 209 & 1 & & & \\
\hline$>21.7-30.5$ & 364 & 245 & 1.15 & $(0.88,1.49)$ & & \\
\hline$>30.5-48.3$ & 365 & 290 & 1.09 & $(0.81,1.46)$ & & \\
\hline$>48.3$ & 364 & 259 & 1.14 & $(0.83,1.57)$ & & \\
\hline Total & 1458 & 1003 & ptrend & 0.503 & & \\
\hline Cont. $(10 \mu \mathrm{g} / \mathrm{L})$ & & & 1.01 & $(0.97,1.05)$ & & \\
\hline \multicolumn{7}{|l|}{ Chloroform $(\mu \mathrm{g} / \mathrm{L})$} \\
\hline$\leq 7.6$ & 365 & 198 & 1 & & 1 & \\
\hline$>7.6-18.8$ & 364 & 233 & 1.25 & $(0.95,1.65)$ & 1.22 & $\begin{array}{l}(0.92 \\
1.62)\end{array}$ \\
\hline$>18.8-24.3$ & 365 & 266 & 1.29 & $(0.96,1.73)$ & 1.25 & $\begin{array}{l}(0.95 \\
1.65)\end{array}$ \\
\hline$>24.3$ & 364 & 306 & 1.47 & $(1.05,2.06)$ & 1.40 & $\begin{array}{l}(1.01) \\
1.95)\end{array}$ \\
\hline Total & 1458 & 1003 & ptrend & 0.028 & ptrend & 0.038 \\
\hline Cont. $(10 \mu \mathrm{g} / \mathrm{L})$ & & & 1.12 & $(0.98,1.27)$ & 1.12 & $\begin{array}{l}(0.98 \\
1.27)\end{array}$ \\
\hline \multicolumn{7}{|l|}{ Br-THMs ( $\mu \mathrm{g} / \mathrm{L})$} \\
\hline$\leq 5.5$ & 365 & 276 & 1 & & 1 & 1.00 \\
\hline$>5.5-10.1$ & 364 & 282 & 1.08 & $(0.82,1.41)$ & 1.16 & $\begin{array}{l}(0.84 \\
1.59)\end{array}$ \\
\hline$>10.1-31.0$ & 365 & 197 & 0.79 & $(0.57,1.10)$ & 0.90 & $\begin{array}{l}(0.64 \\
1.25)\end{array}$ \\
\hline$>31.0$ & 364 & 248 & 0.91 & $(0.68,1.23)$ & 0.95 & $\begin{array}{l}(0.67 \\
1.35)\end{array}$ \\
\hline $\begin{array}{l}\text { Total } \\
\text { Cont. }(10 \mu \mathrm{g} / \mathrm{L})\end{array}$ & 1458 & 1003 & $\begin{array}{l}\text { ptrend } \\
1.00\end{array}$ & $\begin{array}{l}0.275 \\
(0.96,1.04)\end{array}$ & $\begin{array}{l}\text { ptrend } \\
0.99\end{array}$ & $\begin{array}{l}0.378 \\
(0.96 \\
1.03)\end{array}$ \\
\hline
\end{tabular}

TTHMs: total trihalomethanes. Br-THMs: brominated trihalometanes. Mixed models with area as random effect. Exposure variables are categorized into quartiles.

In bold are the statistically significant odds ratios. P values for trend are shown in italics.

${ }^{a}$ Models adjusted for age, educational level, occupational status, family history of BC, BMI, energy intake, physical activity, oral contraceptive use and menopause treatment use.

${ }^{\mathrm{b}}$ Models mutually adjusted for chloroform and Br-THMs.

also related to $\mathrm{BC}(\mathrm{OR}=1.76(95 \% \mathrm{CI}=0.80,3.90)$ for the highest $(>91.8 \mu \mathrm{g} / \mathrm{L})$ vs. lowest $(<48.8 \mu \mathrm{g} / \mathrm{L})$ quartiles of Br-THMs and $\mathrm{OR}=1.72(95 \% \mathrm{CI}=0.79,3.78)$ for the highest $(>110.5 \mu \mathrm{g} / \mathrm{L}) \mathrm{vs}$. lowest $(<71.1 \mu \mathrm{g} / \mathrm{L})$ quartiles of TTHMs) (Table S6). Madrid, the largest city in Spain and the study area contributing with more subjects, had very low variability in THM levels and no association between those and BC was detected (Table S6).

Average residential THM levels during the last 10 years were highly correlated to average adult-life levels (spearman correlations of 0.80 , 0.92 and 0.85 for TTHMs, Br-THMs and chloroform, respectively (all pvalues < 0.001)). OR of BC for residential THM levels in the last 10 years were therefore very similar to those for adult-life time residential THM levels (Table S7).

Approximately $75 \%$ of the study population usually drank municipal water in their longest residence (28.4 years duration in average), while $21 \%$ drank bottled water, and type of water consumed was not related to BC (Table 3). The median weekly duration for showering and washing dishes by hand was $40 \mathrm{~min}(\mathrm{IQR}=30,70)$ and $140 \mathrm{~min}$ $(\mathrm{IQR}=35,210)$, respectively, and they were not correlated (Spearman correlation $=0.004)$. Hand dish-washing was associated with $\mathrm{BC}$ with an OR of $1.39(95 \% \mathrm{CI}=1.05,1.83)$ for the highest vs. lowest quartile (p-trend of 0.013), also after adjusting by residential TTHMs. When combining residential THM levels with water activities, the estimated ingested THM levels were not associated with BC (Table 4). Some intermediate category of exposure to TTHMs and Br-THMs through showering was protective for $\mathrm{BC}$, while exposure through dish washing was positively related to $\mathrm{BC}(\mathrm{OR}=1.93 ; 95 \% \mathrm{CI}=1.47,1.12$ for the highest vs. lowest quartiles of TTHMs). Further adjustment by 
Table 3

Frequency of water-related activities in the study population and related odds ratio (OR) and $95 \%$ confidence interval (CI) of breast cancer.

\begin{tabular}{|c|c|c|c|c|c|c|}
\hline & \multicolumn{2}{|c|}{ Controls } & \multicolumn{2}{|c|}{ Cases } & \multirow[t]{2}{*}{ OR } & \multirow[t]{2}{*}{$95 \% \mathrm{CI}$} \\
\hline & $\mathrm{N}$ & $\%$ & $\mathrm{~N}$ & $\%$ & & \\
\hline \multicolumn{7}{|l|}{ Drinking water source $^{a}$} \\
\hline Tap/municipal & 1101 & 75.6 & 749 & 75.0 & 1 & \\
\hline Bottled & 304 & 20.9 & 207 & 20.7 & 0.99 & $(0.79,1.23)$ \\
\hline Wells/springs/other & 51 & 3.5 & 42 & 4.2 & 1.07 & $(0.68,1.68)$ \\
\hline Total & & & & 2454 & & \\
\hline \multicolumn{7}{|l|}{ Showering (min/week) } \\
\hline$\leq 30$ & 374 & 26.5 & 260 & 26.5 & 1 & \\
\hline$>30-40$ & 356 & 25.2 & 265 & 27.0 & 0.95 & $(0.75,1.22)$ \\
\hline$>40-70$ & 494 & 35.0 & 336 & 34.2 & 0.83 & $(0.66,1.04)$ \\
\hline \multirow[t]{2}{*}{$>70$} & 188 & 13.3 & 121 & 12.3 & 0.82 & $(0.61,1.10)$ \\
\hline & & & & 2394 & ptrend & 0.070 \\
\hline \multicolumn{7}{|c|}{$\begin{array}{l}\text { Dish washing by hand (min/ } \\
\text { week) }\end{array}$} \\
\hline$\leq 35$ & 357 & 25.9 & 236 & 26.1 & 1 & \\
\hline $35-140$ & 439 & 31.9 & 271 & 29.9 & 0.95 & $(0.75,1.20)$ \\
\hline$>140-210$ & 279 & 20.2 & 182 & 20.1 & 1.10 & $(0.84,1.45)$ \\
\hline \multirow[t]{2}{*}{$>210$} & 303 & 22.0 & 216 & 23.9 & 1.39 & $\begin{array}{l}(1.05 \\
1.83)\end{array}$ \\
\hline & & & & 2283 & ptrend & 0.013 \\
\hline
\end{tabular}

Mixed models with area as random effect. Exposure variables are categorized into quartiles. Models adjusted for age, educational level, occupational status, family history of BC, BMI, energy intake, physical activity, oral contraceptive use and menopause treatment use.

In bold are the statistically significant odds ratios. $\mathrm{P}$ values for trend are shown in italics.

a Drinking water source in the longest residency.

residential level of chloroform or Br-THMs did not affect the associations (results not shown).

\section{Discussion}

For the first time, we estimated the association between life-time exposure to THMs in drinking water and female BC in a large casecontrol study, including areas with contrasting THM concentrations in Spain and evaluating different routes of exposure and THM species. At common levels in Europe, total THM exposure was not related to BC, but a positive association was suggested for exposure to chloroform.
This case-control study includes several areas in Spain with a large variability in Br-THMs and TTHM levels in drinking water. The proportion and correlation between chloroform and Br-THMs also varied considerably between areas, allowing detecting different associations with BC by THM species. When comparing the highest vs. lowest quartiles of exposure, residential chloroform in drinking water was associated with BC at $>24 \mu \mathrm{g} / \mathrm{L}$, while no association was detected for Br-THMs at $>31 \mu \mathrm{g} / \mathrm{L}$ or for TTHM at $>48 \mu \mathrm{g} / \mathrm{L}$. However, the GAM models indicated a positive linear association with BC not only for chloroform but also for TTHM and Br-THMs, but a reduced number of subjects were exposed at the highest levels. A 7\% of study participants had a median lifetime residential TTHM levels above the current maximum level in the $\mathrm{EU}$ of $100 \mu \mathrm{g} / \mathrm{L}$. These subjects were from the Barcelona metropolitan area, where Br-THMs have been especially high (median of $64.4 \mu \mathrm{g} / \mathrm{L}$ and $\mathrm{IQR}=48.8,91.8$ ) due to a high bromide content in the raw water. In this area, an increased OR was also detected for life-time exposure to TTHMs and Br-THMs, although this was not statistically significant probably due to the reduced sample size.

These results are difficult to compare since previous studies on DBP exposure and BC did not report DBP levels (Gottlieb et al., 1982; Kanarek and Young, 1982; Koivusalo et al., 1997; Vinceti et al., 2004; Young et al., 1981), but were based on surrogates of DBP exposure such as chlorinated vs. unchlorinated water (Kanarek and Young, 1982; Koivusalo et al., 1997) or groundwater vs. surface water (Doyle et al., 1997). One exception is an ecological study in North Carolina published in 1998 (Marcus et al., 1998) that compared female BC rates by current levels of TTHMs and found a rate ratio of $1.1(95 \% \mathrm{CI}=0.9,1.2)$ for $>80 \mu \mathrm{g} / \mathrm{L}$ vs. $<40 \mu \mathrm{g} / \mathrm{L}$ (Marcus et al., 1998). A large study using data from the cancer registry in Finland also found a small increased risk of $\mathrm{BC}(\mathrm{RR}=1.11(95 \% \mathrm{CI}=1.01,1.22))$ among women supplied by chlorinated surface water (Koivusalo et al., 1997). A part from a poor exposure assessment, previous epidemiological studies on BC and DBP exposure had other important methodological constrains, such as an ecological design (Marcus et al., 1998; Vinceti et al., 2004; Wilkins and Comstock, 1981), the use of mortality instead of incidence data (Kanarek and Young, 1982; Vinceti et al., 2004; Wilkins and Comstock, 1981) or a poor assessment of relevant confounders. Therefore, the present study overcomes several limitations of previous studies and represents a step forward in the epidemiological evidence on DBP exposure and $\mathrm{BC}$ risk.

Table 4

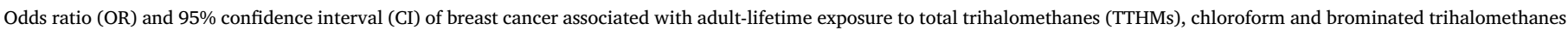
(Br-THMs) through different exposure situations. $\mathrm{N}=2461$.

\begin{tabular}{|c|c|c|c|c|c|c|c|c|c|c|c|c|c|c|}
\hline TTHMs & Contr. & Cases & OR & 95\%CI & $\mathrm{CHCl}_{3}$ & Contr. & Cases & OR & $95 \% \mathrm{CI}$ & Br-THMs & Contr. & Cases & OR & TTHMs \\
\hline \multicolumn{15}{|c|}{ Ingestion ( $\mu \mathrm{g} /$ day) } \\
\hline$\leq 15.0$ & 366 & 254 & 1 & & $\leq 5.5$ & 365 & 248 & 1 & & $\leq 3.6$ & 366 & 254 & 1 & \\
\hline$>15.0-23.8$ & 363 & 204 & 0.91 & $(0.71,1.18)$ & $>5.5-13.4$ & 364 & 201 & 0.88 & $(0.68,1.13)$ & $>3.6-6.7$ & 363 & 273 & 1.04 & $(0.81,1.32)$ \\
\hline$>23.8-32.3$ & 365 & 262 & 1.00 & $(0.77,1.29)$ & $>13.4-23.1$ & 365 & 275 & 1.16 & $(0.90,1.50)$ & $>6.7-12.6$ & 365 & 233 & 0.94 & $(0.72,1.22)$ \\
\hline$>32.3$ & 364 & 282 & 1.05 & $(0.82,1.35)$ & $>23.1$ & 364 & 278 & 0.95 & $(0.71,1.27)$ & $>12.6$ & 364 & 242 & 1.06 & $(0.81,1.39)$ \\
\hline Total & 1458 & 1002 & ptrend & 0.650 & Total & 1458 & 1002 & ptrend & 0.851 & Total & 1458 & 1002 & ptrend & 0.839 \\
\hline \multicolumn{15}{|c|}{ Showering $(\mu \mathrm{g} / \mathrm{L} * \mathrm{~h} /$ week) } \\
\hline$\leq 13.6$ & 353 & 243 & 1 & & $\leq 5.6$ & 353 & 202 & 1 & & $\leq 3.9$ & 353 & 299 & 1 & \\
\hline $13.6-23.1$ & 353 & 270 & 0.99 & $(0.77,1.26)$ & $5.6-11.8$ & 353 & 248 & 1.19 & $(0.92,1.53)$ & $3.9-7.6$ & 353 & 236 & 0.72 & $(0.56,0.92)$ \\
\hline$>23.1-40.0$ & 353 & 202 & 0.65 & $(0.50,0.85)$ & $>11.8-21.0$ & 353 & 285 & 1.16 & $(0.88,1.52)$ & $>7.6-18.9$ & 353 & 192 & 0.59 & $(0.45,0.78)$ \\
\hline$>40.0$ & 353 & 267 & 0.91 & $(0.69,1.20)$ & $>21.0$ & 353 & 247 & 0.93 & $(0.70,1.24)$ & $>18.9$ & 353 & 255 & 0.76 & $(0.57,1.01)$ \\
\hline Total & 1412 & 982 & ptrend & 0.084 & Total & 1412 & 982 & ptrend & 0.497 & Total & 1412 & 982 & ptrend & 0.018 \\
\hline \multicolumn{15}{|c|}{ Dishwashing ( $\mu \mathrm{g} / \mathrm{L} * \mathrm{~h} /$ week) } \\
\hline 13.6 & 345 & 222 & 1 & & $\leq 4.8$ & 345 & 211 & 1 & & $\leq 3.8$ & 345 & 245 & 1 & \\
\hline $13.6-55.7$ & 344 & 198 & 0.96 & $(0.74,1.25)$ & $4.8-26.5$ & 344 & 196 & 1.05 & $(0.80,1.36)$ & $3.8-18.1$ & 344 & 223 & 0.90 & $(0.70,1.15)$ \\
\hline$>$ 55.7-119.9 & 345 & 210 & 1.01 & $(0.78,1.30)$ & $>26.5-57.7$ & 345 & 241 & 1.20 & $(0.93,1.55)$ & $>18.1-58.3$ & 345 & 173 & 0.80 & $(0.61,1.05)$ \\
\hline$>119.9$ & 344 & 275 & 1.47 & $(1.12,1.93)$ & $>57.7$ & 344 & 257 & 1.34 & $(1.03,1.73)$ & $>58.3$ & 344 & 264 & 1.41 & $(1.04,1.92)$ \\
\hline Total & 1378 & 905 & ptrend & 0.009 & Total & 1378 & 905 & ptrend & 0.017 & Total & 1378 & 905 & ptrend & 0.154 \\
\hline
\end{tabular}

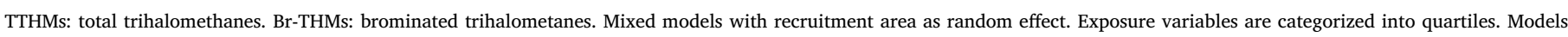
adjusted by age, educational level, occupational status, family history of BC, BMI, energy intake, physical activity, oral contraceptive use and menopause treatment use.

Captions indicating sections (e.g. Introduction, Methods, Results, Discussion) are in bold. P values for trend are shown in italics. 
Another novelty of the present study is the evaluation of individual patterns of water use such as type of ingested water or the frequency and duration of showering and hand dish-washing. Different health effects could be expected by these water activities since they reflect different exposure routes (ingestion, dermal absorption or inhalation) and different THM uptakes (Gordon et al., 2006). The significant association detected between BC and exposure to chloroform was seen for residential levels but not for ingested chloroform. Similarly, residential TTHM levels has been the exposure indicator more related to bladder cancer (Costet et al., 2011; Villanueva et al., 2007) and ingested TTHM was also not related to this cancer in the largest international metaanalysis (Costet et al., 2011). On one hand, residential THM levels are considered an indicator of global exposure regardless of the route (Costet et al., 2011) and on the other hand, the lack of association between cancer and ingested THM levels could be attributed to limitations in the measurement of the indicator more than to a real lack of effect of ingested DBPs (Costet et al., 2011). This is the first study on THM exposure and cancer risk to consider exposure through hand dishwashing and it was positively related to BC. Although THM uptake is lower when washing dishes by hand than when showering (Gordon et al., 2006), the duration of exposure and variability was much higher for hand dish-washing than showering (median of 140 and $40 \mathrm{~min} /$ week, respectively) in this study population limited to women. However, the fact that some protective association was seen between BC and showering and that hand dish-washing was related to $\mathrm{BC}$ risk beyond THM levels, suggests potential confounding by other unmeasured factors.

The modelling of historical THM levels allowed us to estimate exposure for different temporal windows. However, very similar results were found between adult-lifetime exposure and exposure during the last 10 years, probably due to the high correlation between the levels at different exposure periods. Although the present study has done a huge improvement in exposure assessment compared to previous studies, some measurement error is probably still present due to the limited historical THM measurements. To minimize this, we exclude subjects having estimated THM levels for $<70 \%$ of the exposure window. Inability to account for THM exposure outside the home may have introduced error in the estimation of ingested THM levels, although most of total water was consumed at home $(74 \%)$. Selection bias might be another concern, since response rates were low especially among controls that were population-based and shared for different cancer sites within a larger multi-case control study, leading a slightly different age distribution than cases and higher educational level than general population. However, we assume that probability of participation is independent from the exposure, and we don't expect an impact on the results due to response rates. Finally, we cannot rule out uncontrolled confounding by other water contaminants beyond DBPs. However, long-term exposure assessment to nitrate was conducted in this study (Espejo-Herrera et al., 2016) and adjusting models by nitrate exposure did not modified the results. Furthermore, unpublished data on selected pesticides in drinking water in the study area (e.g., simazine, atrazine, terbuthylazine) showed levels below or around the quantification limit. Residual confounding by socioeconomic status could be another concern, although different sensitivity analyses indicate no major effects of socioeconomic status on the estimated risks.

Gastrointestinal and urinary tract, and not $\mathrm{BC}$, are the cancer sites with higher biological plausibility to be affected by DBP exposure (Koivusalo et al., 1997). However, biological mechanisms have been poorly investigated (Nieuwenhuijsen et al., 2009), being genotoxicity and carcinogenicity the most recognized ones (Richardson et al., 2007). Epigenetic changes in DNA methylation have also been suggested as another potential mechanism of DBP toxicity (Salas et al., 2015). DBPs are not considered important endocrine disruptors, but very little toxicological evidence is available (Klinefelter et al., 2004). A toxicological study described a delay in reproductive development in rats due to long-term exposure to brominated haloacetic acids (Klinefelter et al.,
2004) and MX was found to be a potent carcinogen in rats that increased mammary gland tumours in female rats (Komulainen et al., 1997). BC is a heterogeneous disease with potentially different aetiologies in pre- and postmenopausal women and in this study we found slightly higher associations between THM exposure and BC among premenopausal women at the highest exposure category.

DBPs constitute a complex mixture with around 600 identified chemicals with different toxicity (Richardson et al., 2007). THMs are usually the more prevalent DBPs in drinking water but have lower toxicity than other less prevalent DBPs, such as haloacetonitriles or MX (Richardson et al., 2007). During the recruitment period of the present study, several DBPs were analyzed in drinking water of a representative sample across study areas (Villanueva et al., 2012). Haloacetic acids (HAAs) were in a very similar range than TTHMs (median of $26.4 \mu \mathrm{g}$ / L). Haloacetonitries, haloketones, chloropicrin and chloralhydrate were in much lower levels and below the limit of detection in several samples. MX showed a median (range) concentration of 16.7 (0.8-54.1) ng/ L. Chloroform concentration was positively correlated to chlorinated HAA and MX levels, while Br-THMs were positively correlated to brominated HAA (Villanueva et al., 2012).

Epidemiological studies on DBP exposure and cancer risk have mainly used TTHMs as an indicator of exposure to the total mixture of DBPs (Villanueva et al., 2015). This may result in the misclassification of exposure to the relevant chemicals for a given health outcome, since the correlation between DBP constituents is complex and varies across areas and over time (Villanueva et al., 2012). Measuring the exposure to chloroform and Br-THMs allows estimating separately the exposure to overall chlorinated DBPs and brominated DBPs, since these species are usually correlated between them (Villanueva et al., 2012). This may be especially relevant in epidemiological studies including areas with different chlorine-bromine speciation, like the present one. In this study, female BC appeared to be associated with lifetime exposure to common levels of chloroform but not Br-THMs or TTHMs. Chlorinated DBPs are usually found in higher concentrations in drinking water than brominated DBPs, but toxicological evidence indicates that the brominated are more genotoxic and cytotoxic than their chlorinated analogues (Richardson et al., 2007). Furthermore, current concentrations of MX in the study area were positively correlated to current chloroform level and negatively correlated to Br-THMs (Villanueva et al., 2012).

\section{Conclusions}

At common levels in Europe, long-term residential total THMs were not related to female breast cancer. A moderate association with chloroform was suggested at the highest exposure category. These results should be confirmed in future large and well design epidemiological studies, since they would have a large public health impact due to the ubiquity of DBP exposure and the health burden of BC.

\section{Acknowledgements}

We appreciate the contribution of the institutions and local governments that provided data on municipal water.

\section{Funding}

This work was supported by the Acción Transversal del Cáncer del Consejo de Ministros del 11/10/2007, from the Instituto de Salud Carlos III-FEDER (PI08/1770, PI08/0533, PI11/00226, PI11/02213, PI14/00613) FIS grants and Hiwate EU project (036224), Catalan Government DURSI grant 2014SGR647. ISGlobal is a member of the CERCA Programme, Generalitat de Catalunya.

\section{Appendix A. Supplementary data}

Supplementary data to this article can be found online at https:// 
doi.org/10.1016/j.envint.2017.12.031.

\section{References}

Brody, J.G., Rudel, R.A., 2003. Environmental pollutants and breast cancer. Environ. Health Perspect. 111, 1007-1019.

Brody, J.G., Moysich, K.B., Humblet, O., Attfield, K.R., Beehler, G.P., Rudel, R.A., 2007. Environmental pollutants and breast cancer: epidemiologic studies. Cancer 109 (12 Suppl), 2667-2711 (Review).

Castaño-Vinyals, G., Aragonés, N., Pérez-Gómez, B., Martín, V., Llorca, J., Moreno, V., et al., 2015. Population-based multicase-control study in common tumors in Spain (MCC-Spain): rationale and study design. Gac. Sanit. 29 (4), 308-315. http://dx.doi. org/10.1016/j.gaceta.2014.12.003.

Costet, N., Villanueva, C.M., Jaakkola, J.J., Kogevinas, M., Cantor, K.P., King, W.D., et al., 2011. Water disinfection by-products and bladder cancer: is there a European specificity? A pooled and meta-analysis of European case-control studies. Occup. Environ. Med. 68 (5), 379-385.

Doyle, T.J., Zheng, W., Cerhan, J.R., Hong, C.P., Sellers, T.A., Kushi, L.H., et al., 1997. The association of drinking water source and chlorination by-products with cancer incidence among postmenopausal women in Iowa: a prospective cohort study. Am. J. Public Health 87, 1168-1176.

Espejo-Herrera, N., Gracia-Lavedan, E., Pollan, M., Aragonés, N., Boldo, E., Perez-Gomez, B., et al., 2016. Ingested nitrate and breast cancer in the Spanish Multicase-Control Study on Cancer (MCC-Spain). Environ. Health Perspect. 124 (7), 1042-1049.

Font-Ribera, L., Kogevinas, M., Nieuwenhuijsen, M.J., Grimalt, J.O., Villanueva, C.M., 2010. Patterns of water use and exposure to trihalomethanes among children in Spain. Environ. Res. 110, 571-579.

GLOBOCAN, 2012. International Agency for Research on Cancer 2017. Avilable online: http://gco.iarc.fr/today/home.

Gordon, S.M., Brinkman, M.C., Ashley, D.L., Blount, B.C., Lyu, C., Masters, J., et al., 2006. Changes in breath trihalomethane levels resulting from household water-use activities. Environ. Health Perspect. 114 (4), 514-521.

Gottlieb, M.S., Carr, J.K., Clarkson, J.R., 1982. Drinking water and cancer in Louisiana: a retrospective mortality study. Am. J. Epidemiol. 116, 652-667.

Hankinson, S.E., Colditz, G.A., Willett, W.C., 2004. Towards an integrated model for breast cancer etiology: the lifelong interplay of genes, lifestyle, and hormones. Breast Cancer Res. 6 (5), 213-218.

Kanarek, M.S., Young, T.B., 1982. Drinking water treatment and risk of cancer death in Wisconsin. Environ. Health Perspect. 46, 179-186.

Klinefelter, G.R., Strader, L.F., Suarez, J.D., Roberts, N.L., Goldman, J.M., Murr, A.S. 2004. Continuous exposure to dibromoacetic acid delays pubertal development and compromises sperm quality in the rat. Toxicol. Sci. 81, 419-429.

Koivusalo, M., Pukkala, E., Vartiainen, T., Jaakkola, J.J., Hakulinen, T., 1997. Drinking water chlorination and cancer: a historical cohort study in Finland. Cancer Causes
Control 8, 192-200.

Komulainen, H., Kosma, V.M., Vaittinen, S.L., Vartiainen, T., Kaliste-Korhonen, E., Lötjönen, S., et al., 1997. Carcinogenicity of the drinking water mutagen 3-chloro-4(dichloromethyl)-5-hydroxy-2(5H)-furanone in the rat. J. Natl. Cancer Inst. 89, 848-856.

Macon, M.B., Fenton, S.E., 2013. Endocrine disruptors and the breast: early life effects and later life disease. J. Mammary Gland Biol. Neoplasia 18 (1), 43-61.

Marcus, P.M., Savitz, D.A., Millikan, R.C., Morgenstern, H., 1998. Female breast cancer and trihalomethane levels in drinking water in North Carolina. Epidemiology 9, $156-160$.

Nieuwenhuijsen, M.J., Grellier, J., Smith, R., Iszatt, N., Bennett, J., Best, N., Toledano, M., 2009. The epidemiology and possible mechanisms of disinfection by-products in drinking water. Phil. Trans. R. Soc. A 367, 4043-4076.

Pollán, M., Pastor-Barriuso, R., Ardanaz, E., Argüelles, M., Martos, C., Galcerán, J., et al., 2009. Recent changes in breast cancer incidence in Spain, 1980-2004. J. Natl. Cancer Inst. 101 (22), 1584-1591.

Richardson, S.D., Plewa, M.J., Wagner, E.D., Schoeny, R., Demarini, D.M., 2007. Occurrence, genotoxicity, and carcinogenicity of regulated and emerging disinfection by-products in drinking water: a review and roadmap for research. Mutat. Res. 636 (1-3), 178-242.

Salas, L.A., Bustamante, M., Gonzalez, J.R., Gracia-Lavedan, E., Moreno, V., Kogevinas, M., et al., 2015. DNA methylation levels and long-term trihalomethane exposure in drinking water: an epigenome-wide association study. Epigenetics 10 (7), 650-661.

Villanueva, C.M., Cantor, K.P., Grimalt, J.O., Malats, N., Silverman, D., Tardon, A., et al., 2007. Bladder cancer and exposure to water disinfection by-products through ingestion, bathing, showering, and swimming in pools. Am. J. Epidemiol. 165 (2), $148-156$.

Villanueva, C.M., Castaño-Vinyals, G., Moreno, V., Carrasco-Turigas, G., Aragonés, N., Boldo, E., et al., 2012. Concentrations and correlations of disinfection by-products in municipal drinking water from an exposure assessment perspective. Environ. Res. $114,1-11$.

Villanueva, C.M., Cordier, S., Font-Ribera, L., Salas, L.A., Levallois, P., 2015. Overview of disinfection by-products and associated health effects. Curr. Environ. Health Rep. 2 (1), 107-115.

Vinceti, M., Fantuzzi, G., Monici, L., Cassinadri, M., Predieri, G., Aggazzotti, G., 2004. A retrospective cohort study of trihalomethane exposure through drinking water and cancer mortality in northern Italy. Sci. Total Environ. 330, 47-53.

Wilkins, J.R., Comstock, G.W., 1981. Source of drinking water at home and site-specific cancer incidence in Washington County, Maryland. Am. J. Epidemiol. 114, 178-190.

Young, T.B., Kanarek, M.S., Tsiatis, A.A., 1981. Epidemiologic study of drinking water chlorination and Wisconsin female cancer mortality. J. Natl. Cancer Inst. 67 (6), 1191-1198.

Zierler, S., Danley, R.A., Feinodd, L., 1986. Type of disinfectant in drinking water and pattems of mortality in Massachusetts. Environ. Health Perspect. 69, 275-279. 